\title{
PERBEDAAN KEMAMPUAN KOGNITIF SISWA MENGGUNAKAN MODEL PEMBELAJARAN KANCING GEMERINCING DAN JIGSAW PADA PEMBELAJARAN TEMATIK TEMA 9 KELAS V SD
}

\author{
Lutfi Alimatus Sholehah \\ SDN Tulusrejo 2 \\ e-mail lutfias99@gmail.com
}

\begin{abstract}
Cooperative learning ringing button and jigsaw model is two learning model which has similarity and different characteristic. The research type is quasi experiment research. Research variables consist of Independent variable which is ringing button learning model and jigsaw and dependent variable, which is student cognitive skill. Research sample consist of two grade V which are class VA Muhammadiyah 4 Batu Elementary school. The research is measured using Independent Sample T-test with the help of SPSS 17 for windows. Research shows that post-test found $t_{\text {count }}$ value for $-0,970$ with significance for $0,336 t_{\text {table }}$ value in free degree of 56 and real rate 0,05 for 2,003. When there's comparison, so that $t_{\text {count }}<t_{\text {table }}$ or significance $>0,05$ and concluded that Ho is accepted which means there's no significant difference is students' cognitive skill using ringing button and jigsaw learning model.
\end{abstract}

Keyword:Cognitive abilities, learning models, Jinks, Jigsaw, thematic learning.

\begin{abstract}
Abstrak:.Pembelajaran kooperatif model Kancing Gemerincing dan Jigsaw merupakan dua modelajaran yang memiliki memiliki perbedan karakteristik. Penelitian ini eksperimen semu. Variabel penelitian terdiri dari variabel bebas yaitu model pembelajaran Kancing Gemerincing dan Jigsaw dan variabel terikat yaitu kemampuan kognitif siswa. Sampel penelitian ini terdiri dari 2 kelas V SD Muhammadiyah 4 Batu tahun ajaran 2014/2015 yaitu kelas VA yang berjumlah 30 siswa dan kelas VB yang berjumlah 30 siswa.Analisis data dilakukan dengan uji normalitas, uji homogenitas, dan uji hipotesis menggunakan Independent Sample T-Test dengan bantuan SPSS 17 for windows.Hasil penelitian menunjukan bahwa post-test diperoleh nilai thitung sebesar -0,970 dengan nilai signifikansi sebesar 0,336. Nilai $t_{\text {tabel }}$ pada derajat bebas 56 dan taraf nyata 0,05 sebesar 2,003. Apabila dilakukan pembandingan maka $\left|t_{\text {hitung }}\right|<t_{\text {tabel }}$ atau nilai signifikansi $>0,05$ disimpulkan Ho diterima yang berarti bahwa tidak terdapat perbedaan yang signifikan kemampuan kognitif siswa yang menggunakan model pembelajaran Kancing Gemerincing dan Jigsaw.
\end{abstract}

Kata Kunci:Kemampuan kognitif, model pembelajaran, Kancing Gemerincing, Jigsaw, pembelajaran tematik

\section{PENDAHULUAN}

Pendidikan merupakan salah satu faktor yang sangat strategis dan substansional dalam upaya peningkatan kualitas Sumber Daya Manusia (SDM) suatu bangsa yang diharapkan mampu membawa perubahan ke jenjang lebih baik bagi suatu bangsa dan negara. Hal ini sesuai dengan UU No.20 Tahun 2003 tentang Sistem Pendidikan Nasional Bab 1 ayat 1 menyatakan bahwa pendidikan adalah usaha sadar dan terencana untuk mewujudkan suasana belajar dan proses pembelajaran agar siswa secara aktif mengembangkan potensi dirinya untuk memiliki kekuatan spiritual keagamaan, pengendalian diri, kepribadian, kecerdasan, akhlak mulia, serta keterampilan yang diperlukan dirinya, masyarakat, bangsa dan negara.
Mengingat begitu pentingnya pendidikan maka perlu adanya suatu pembaharuan pendidikan. Tiga komponen utama yang penting dalam konteks pembaharuan pendidikan, yaitu kurikulum, peningkatan kualitas pembelajaran, dan efektivitas model pembelajaran (Nurhadi dkk, 2009:1). Pembaharuan kurikulum yang berkelanjutan merupakan keharusan agar sistem pendidikan nasional selalu relevan dan kompetitif (Mulyasa, 2007:22).

Pengembangan dan pembaharuan kurikulum KTSP menjadi kurikulum 2013 dilatar belakangi oleh adanya kelemahan pada kurikulum KTSP (Kemendikbud, 2012). Pengembangan kurikulum 2013 menjanjikan lahirnya generasi penerus bangsa yang produktif, kreatif, inovatif dan berkarakter sehingga 
tercapainya tujuan pendidikan (Mulyasa, 2013:39).

Selain pembaharuan kurikulum, komponen utama pada pembaharuan pendidikan adalah peningkatan kualitas pembelajaran dan efektivitas model pembelajaran yang dapat dilakukan melalui kegiatan pendidikan di sekolah. Melalui model pembelajaran guru dapat membantu siswa mendapatkan informasi, ide, ketrampilan, cara berpikir, dan mengekspresikan ide (Suprijono, 2009:46).

Salah satu model pembelajaran yang dapat digunakan guru adalah model pembelajaran Kooperatif. Model pembelajaran kooperatif yaitu suatu model pembelajaran dimana siswa belajar dan bekerja dalam kelompokkelompok kecil secara kolaboratif yang beranggotakan 4-6 orang dengan struktur kelompok heterogen (Slavin,2005:8). Model pembelajaran kooperatif dapat diterapkan untuk memotivasi siswa berani mengemukakan pendapatnya, menghargai teman, dan saling memberikan pendapat (Isjoni, 2012:13).

Model pembelajaran kooperatif terdapat banyak tipe yang dapat digunakan dalam proses kegiatan belajar mengajar. Model pembelajaran kooperatif model Jigsaw dan Kancing Gemerincing merupakan tipe dari pembelajaran kooperatif.Model pembelajaran kooperatif tipe kancing gemerincingadalah suatu teknik pembelajaran kooperatif yang menggunakan kancing-kancing atau benda-benda kecil lainya sebagai media untuk pola interaksi siswa dalam kelompok belajar sehinggamemiliki keunggulan mengatasi hambatan pemerataan kesempatan yang sering mewarnai kerja kelompok (Huda, 2011:142).

Tipe model pembelajaran kooperatif yang lainnya adalah tipe Jigsaw. Menurut Aronson (dalam Yamin, 2013:90) model pembelajaran kooperatif tipe Jigsaw adalah salah satu jenis strategi pembelajaran kooperatif yang menempatkan siswa dalam kelompok kecil untuk menyelidiki suatu topik umum. Pada intinya model pembelajaran kooperatif tipe Jigsaw menerapkan kerjasama kelompok dengan tingkat kemampuan heterogen dan masing- masing siswa bertanggung jawab atas satu bahan materi, sehingga memiliki keunggulan untuk mengembangkan kreativitas, kemampuan dan daya pemecahan menurut kehendaknya sendiri (Shoimin, 2014:93-94).

Model pembelajaran Kancing Gemerincing dan Jigsaw merupakan dua model pembelajaran yang memiliki kesamaan dan perbedaan karakteristik. Kancing gemerincing dan Jigsaw mempunyai keunggulan yang menguntungkan dalam proses kegitan belajar sehingga dapat meningkatkan hasil belajar siswa. Peryataan tersebut dapat diperoleh dengan adanya penelitian sebelumnya.

Hasil penelitian yang pernah dilakukan oleh Harsyiwi (2013) dengan judul "Penerapan Model Pembelajaran Kooperatif Teknik Kancing Gemerincing untuk Meningkatkan Hasil Belajar Matematika Materi Operasi Perkalian dan Pembagian Siswa kelas VI SD Negeri 1 Kembang Kabupaten Jepara". Penelitian ini menunjukan bahwa penerapan model pembelajaran Kooperatif tipe Kancing Gemerincing dapat meningkatkan hasil belajar Matematika.

Model Pembelajaran Kooperatif Tipe Jigsaw juga telah diketahui meningkatkan kemampuan kognitif siswa. Hal ini sesuai dengan penelitian yang dilakukan oleh Ilma (2010) dengan judul "Perbedaan Kemampuan Kognitif dan Ketrampilan Kooperatif Model Jigsaw dan Cooperatif Script siswa kelas VII MTS Muhammadiyah 1 Malang", menunjukan bahwa kemampuan kognitif siswa yang diajarkan dengan model pembelajaran tipe jigsaw lebih baik dari pada yang diajarkan dengan model pembelajaran Cooperatif Script.

Observasi telah dilakukan di SD Muhammadiyah 4 Batu pada bulan Februari 2015, pembelajarannya sudah menggunakan kurikulum 2013 dan menerapkan model pembelajaran kooperatif, salah satunya adalah model pembelajaran Jigsaw. Tetapi penerapannya masih belum maksimal dan kurang sesuai dengan langkahlangkah dari model yang diterapkan. Dalam hal ini guru kurang memberikan bimbingan ketika diskusi sehingga masih 
banyak siswa yang tidak melakukan diskusi.

Observasi berkelanjutan pada tanggal 2 maret 2015 sampai dengan tanggal 6 maret 2015 menunjukan masih belum ada perubahan mengenai cara pelaksanaan kegiatan belajar mengajarnya. Banyak siswa yang tidak melalukan diskusi dan hanya mengandalkan temannya untuk menjawab tugas yang diberikan oleh guru. Apabila hal ini diabaikan, keadaan tersebut akan mempengaruhi hasil belajar siswa terutama dalam kemampuan kognitif yang dapat ditandai dengan hasil ujian siswa yang masih banyak dibawah standart ketuntasan minimal.

Kemampuan kognitif merupakan dasar untuk membangun pengetahuan, sikap dan keterampilan motorik dalam pencapaian kompetensi secara utuh sesuai dengan mata pelajaran tertentu (Sudjana, 2013:23). Oleh karena itu, penelitian ini mengukur perbedaan kemampuan kognitifdalam model pembelajaran kooperatif menggunakan tipe Kancing Gemerincing dan Jigsaw karena keduanya diharapkan dapat meningkatkan hasil belajar siswa khususnya dalam kemampuan kognitif. Sehingga penelitian ini berjudul "Perbedaan Kemampuan Kognitif Siswa Menggunakan Model Pembelajaran Kancing Gemerincing dan Jigsaw pada Pembelajaran Tematik Tema 9 Kelas V SD Muhammadiyah 4 Batu".

Adapun rumusan masalah dalam penelitian ini yaitu apakah terdapat perbedaan kemampuan kognitif siswa yang menggunakan model pembelajaran Kooperatif tipe Kancing Gemerincing dengan model Jigsaw pada Tema 9 Lingkungan Sahabat Kita, Sub tema 3 Pelestarian Lingkungan, Pembelajaran 4 kelas VA dan VB SD Muhammadiyah 4 Batu ?. Tujuan dari penelitian ini yaitu menjelaskan perbedaan kemampuan kognitif siswa yang menggunakan model pembelajaran Kooperatif tipe Kancing Gemerincing dengan model Jigsaw pada Tema 9 Lingkungan Sahabat Kita, Sub tema 3 Pelestarian Lingkungan, Pembelajaran 4 kelas VA dan VB SD Muhammadiyah 4 Batu.

\section{KAJIAN PUSTAKA}

\section{Pembelajaran Tematik}

Pembelajaran tematik menerapkan tema-tema yang jauh lebih aktual dan kontekstual dalam kehidupan sehari-hari. Sementara itu, yang dimaksud dengan tema dalam istilah kurikulum tematik adalah pokok pikiran yang menjadi inti pembicaraan atau pembahasan dalam kegiatan pembelajaran (Hajar, 2013:2022).

Pembelajaran tematik dapat diartikan suatu kegiatan pembelajaran dengan mengintegrasikan materi beberapa mata pelajaran dalam satu tema/topik pembahasan. Pembelajaran dalam kurikulum 2013 menekankan pada dimensi pedagogik modern yaitu menggunakan pendekatan ilmiah (scientific approach). Proses pembelajaran tematik menggunakan pendekatan scientific menurut Kemendikbud (2013) dimaksudkan untuk memberikan pemahaman kepada siswa dalam mengenal, memahami berbagai materi menggunakan pendekatan ilmiah, bahwa informasi bisa berasal dari mana saja, kapan saja, tidak bergantung pada informasi searah dari guru. Hal ini karena proses pembelajaran harus menyentuh tiga ranah yaitu sikap, pengetahuan dan keterampilan

\section{Pembelajaran dengan Pendekatan Kooperatif (Cooperatif Learning)}

Teori yang melandasi pembelajaran kooperatif adalah teori konstruktivisme. Pada dasarnya pendekatan teori kontruktivisme dalam belajar adalah suatu pendekatan dimana siswa harus secara individual menemukan dan mentransformasikan informasi kompleks, memeriksa informasi dengan aturan yang ada dan merevisinya bila perlu (Teti Soebari dalam Rusman, 2013:201).
a. Pembelajaran teknik Kancing Gemerincing

Teknik kancing gemerincing adalah suatu teknik pembelajaran kooperatif yang menggunakan kancing-kancinng atau benda-benda kecil lainnya sebagai media untuk pola interaksi siswa dalam kelompok belajar. Pengertian di atas dapat disimpulkan bahwa pembelajaran kooperatif teknik kancing gemerincing menekankan keaktifan semua anggota kelompok dalam menyelesaikan sebuah 
permasalahan yang mampu meningkatkan produktivitas dalam pemecahan masalah, dimana mereka saling membantu satu sama lain untuk mencapai sebuah tujuan yangsama agar hasil belajar mereka bisa meningkat secara merata.

\section{b. Model Pembelajaran Jigsaw}

Model pembelajaran Jigsaw adalah suatu tipe model pembelajaran kooperatif yang terdiri dari beberapa anggota dalam satu kelompok yang bertanggung jawab atas penguasaan bagian materi belajar dan mampu mengajarkan materi tersebut kepada anggota lain dalam kelompoknya (Arend dalam Yamin, 2013:90).

Menurut Rusman (2008 : 205) model pembelajaran jigsaw ini dikenal juga dengan kooperatif para ahli. Karena anggota setiap kelompok dihadapkan pada permasalahan yang berbeda. Namun, permasalahan yang dihadapi setiap kelompok sama, kita sebut sebagai team ahli yang bertugas membahas permasalahan yang dihadapi. Selanjutnya, hasil pembahasan itu di bawah kekelompok asal dan disampaikan pada anggota kelompoknya.

Dalam penerapannya sering dijumpai beberapa permasalahan yaitu :

1. Siswa yang aktif akan lebih mendominasi diskusi, dan cenderung mengontrol jalannya diskusi. Untuk mengantisipasi masalah ini guru harus benar-benar memperhatikan jalannya diskusi. Guru harus menekankan agar para anggota kelompok menyimak terlebih dahulu penjelasan dari tenaga ahli. Kemudian baru mengajukan pertanyaan apabila tidak mengerti.

2. Siswa yang memiliki kemampuan membaca dan berfpikir rendah akan mengalami kesulitan untuk menjelaskan materi apabila ditunjuk sebagai tenaga ahli. Untuk mengantisipasi hal ini guru harus memilih tenaga ahli secara tepat, kemudian memonitor kinerja mereka dalam menjelaskan materi, agar materi dapat tersampaikan secara akurat.

3. Siswa yang cerdas cenderung merasa bosan.
4. Untuk mengantisipasi hal ini guru harus pandai menciptakan suasana kelas yang menggairahkan agar siswa yang cerdas tertantang untuk mengikuti jalannya diskusi.

5. Siswa yang tidak terbiasa berkompetisi akan kesulitan untuk mengikuti proses pembelajaran.

\begin{tabular}{|c|c|c|}
\hline Perbedaan & $\begin{array}{l}\text { Model Kancing } \\
\text { Gemerincing }\end{array}$ & Model Jigsaw \\
\hline $\begin{array}{l}\text { Langkah- } \\
\text { langkah }\end{array}$ & $\begin{array}{l}\text { 1. Guru } \\
\text { mengorganisasik } \\
\text { an siswa kedalam } \\
\text { kelompok } \\
\text { belajar. } \\
\text { Guru } \\
\text { menyiapkan satu } \\
\text { kotak kecil yang } \\
\text { berisi kancing- } \\
\text { kancing. } \\
\text { Masing-masing } \\
\text { anggota dari } \\
\text { setiap kelompok } \\
\text { mendapatkan } 3 \\
\text { buah kancing } \\
\text { (jumlah kancing } \\
\text { bergantung pada } \\
\text { sukar tidaknya } \\
\text { tugas yang } \\
\text { diberikan)Setiap } \\
\text { kali anggota } \\
\text { selesai bicara } \\
\text { atau diu } \\
\text { mengeluarkan } \\
\text { pendapat, dia } \\
\text { harus } \\
\text { menyerahkan } \\
\text { salah satu } \\
\text { kancingya dan } \\
\text { meletaknannya di } \\
\text { tengah-tengah } \\
\text { meja kelompok. } \\
\text { Jika kancing } \\
\text { yang dimiliki } \\
\text { salah seorang } \\
\text { siswa habis, } \\
\text { maka siswa } \\
\text { tersebut tidak } \\
\text { boleh berbicara } \\
\text { lagi sampai } \\
\text { semua rekannya } \\
\text { menghabiskan } \\
\text { kancingnya } \\
\text { masing-masing. } \\
\text { Jika semua } \\
\text { kancing sudah } \\
\text { habis, sedangkan } \\
\text { tugas belum } \\
\text { selesai kelompok } \\
\text { boleh mengambil } \\
\text { kesepakatan } \\
\text { untuk membagi- } \\
\text { bagi kancing lagi } \\
\text { dan mengulang } \\
\text { prosedurnya } \\
\text { kembali }\end{array}$ & 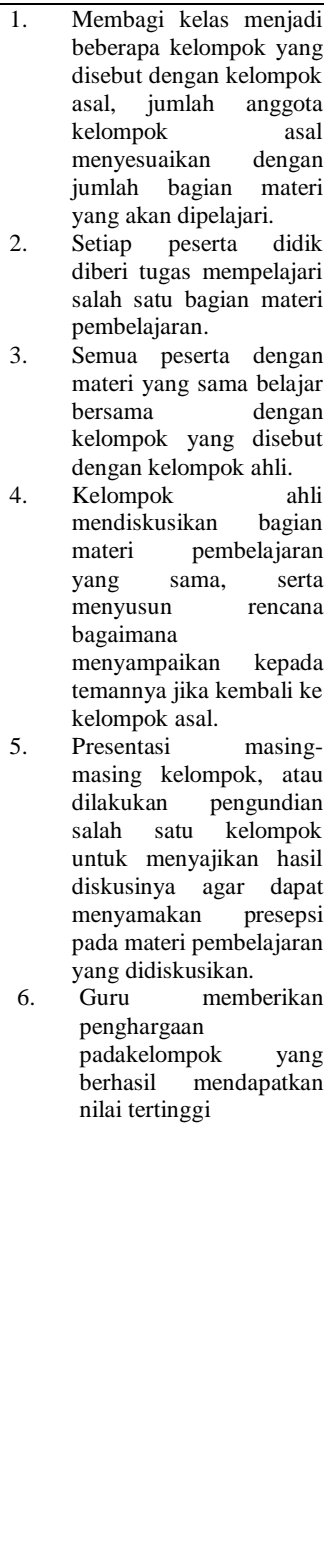 \\
\hline
\end{tabular}

Tabel 1.1 Perbedaan Model Kancing Gemerincing dan Jigsaw(Huda, 2011:142-143)

\section{Klasifikasi Hasil Belajar}

a) Aspek Kognitif yang meliputi pengetahuan, pemahaman, aplikasi, analisis, sintesis, dan evaluasi.

b) Aspek Afektif yang meliputi penerimaan, partisipasi, penilaian, organisasi, dan internalisasi.

c) Aspek Psikomotorik yang meliputi persepsi, kesiapan, gerakan terbimbing, gerakan terbiasa, gerakan kompleks, dan kreativitas. 


\section{METODE}

Metode penelitian ini menggunakan eksperimen semu, dengan membagi kelompok penelitian menjadi dua kelompok eksperimen. Kelompok pertama adalah kelompok eksperimen yang belajar dengan pembelajaran kooperatif model Kancing Gemerincing dan kelompok kedua adalah kelompok eksperimen yang belajar dengan pembelajaran kooperatif model Jigsaw.

Penelitian ini dilaksanakan di SDN Muhammadiyah 4 Batu. Penelitian ini dilaksanakan pada 27-30 Mei 2015 semester II tahun ajaran 2014-2015.

Rancangan penelitian yang digunakan adalah : Two Group, Pretest posttest design.Populasi dalam penelitian ini sebanyak 122 siswa, Cara menentukan sampel dalam penelitian ini adalah menggunakan teknik Cluster Sampling.Sampel penelitian ini terdiri dari 2 kelas yaitu kelas VA dengan jumlah siswa 30 dan kelas VB dengan jumlah siswa 30.Variabel bebas dalam penelitian ini adalah model pembelajaran koperatif tipe Kancing Gemerincing dan Jigsaw.Variabel Terikat dalam penelitian ini adalah kemampuan kognitif siswa.

Instrumen pengukuran yang digunakan pada penelitian ini adalah tes.Teknik pengumpulan data observasi dandokumentasi. normalitas dan uji homogenitas.

\section{HASIL DAN PEMBAHASAN}

Uji Validitas model pembelajaran kancing, dari 25 soal pre-test yang digunakan 5 diantaranya tidak valid yaitu no $5,17,18,23$ dan 25 , Item soal yang tidak valid akan dibuang dan tidak akan masuk dalam perhitungan analisis data.

Model pembelajaran Jigsaw, dari 25 soal pretest yang digunakan 5 diantaranya tidak valid yaitu no $5,17,18$, 23 dan 25. Demikian pula pada posttest, dari 25 soal terdapat 5 yang tidak valid yaitu no $5,17,18,24$ dan 25 .

Hasil uji reliabilitas soal pre-test dan post-test kelompok Kancing Gemerincing menggunakan rumus Sprearman-Brown Unequal Length. Berdasarkan tabel hasil analisis di atas diketahui bahwa koefisien soal pre-test kelompok Kancing Gemerincing adalah
0,582 disimpulkan variabel tersebut telah memiliki reliabilitas yang sedang/cukup. Berdasarkan tabel hasil analisis diketahui bahwa koefisien soal post-test kelompok Kancing Gemerincing adalah 0,852 disimpulkan variabel tersebut telah memiliki reliabilitas yang sangat tinggi.

Tingkat kesukaran model pembelajaran Kancing Gemerincing , dari 25 soal pre-test diperoleh tingkat kesukaran 15 soal mudah dan 10 soal sedang. Sedangkan dari 25 soal post-test diperoleh tingkat kesukaran 21 soal mudah dan 4 soal sedang..

Model pembelajaran Jigsaw, dari 25 soal pre-test diperoleh tingkat kesukaran 14 soal mudah dan 11 soal sedang. Sedangkan soal post-test diperoleh tingkat kesukaran 18 soal mudah dan 7 soal sedang.

Rata-rata hasil belajar siswa sebelum dibelajarkan dengan model pembelajaran Kancing Gemerincing memiliki rata-rata nilai sebesar 70,17. Setelah diberikan pembelajaran dengan model pembelajaran Kancing Gemerincing terjadi peningkatan rata-rata nilai hingga mencapai 81,21. Sedangkan kelompok siswa sebelum dibelajarkan dengan model pembelajaran Jigsaw memiliki rata-rata nilai sebesar 70,00. Setelah dibelajarkan dengan model pembelajaran Jigsaw terjadi peningkatan rata-rata hingga mencapai 75,17.

Pada Uji Normalitas hasil uji normalitas didapatkan nilai signifikansi (p-value) uji Kolmogorov-Smirnov pada masing-masing kelompok lebih besar dari 0,05 sehingga setiap variabel berdistribusi normal atau dapat dikatakan bahwa asumsi normalitas terpenuhi.Hasil Uji Homogenitas Ragam didapatkan nilai signifikansi (p-value) uji Levene pada kedua kelompok eksperimen lebih besar dari 0,05 sehingga disimpulkan bahwa kedua kelompok eksperimen memiliki ragam nilai yang homogen atau dapat dikatakan bahwa asumsi homogenitas ragam terpenuhi.Hasil $\mathrm{Uji} \mathrm{t}$ tidak berpasangan diketahui bahwa pada hasil pretest diperoleh nilai $t_{\text {hitung }}$ sebesar 0,027 dengan nilai signifikansi sebesar 0,979 . Nilai $t_{\text {tabel }}$ pada derajat bebas 56 dan taraf nyata 0,05 sebesar 2,003. Apabila dilakukan pembandingan maka $\left|t_{\text {hitung }}\right|<\mathrm{t}_{\text {tabel }}$ atau nilai signifikansi $>0,05$ dan disimpulkan terima Ho yang berarti 
bahwa tidak terdapat perbedaan yang signifikan nilai hasil pretest antara kelas eksperimen model pembelajaran Kancing Gemerinicing dan Jigsaw.

Hasil belajar posttest diperoleh nilai thitung sebesar - 0,970 dengan nilai signifikansi sebesar 0,336. Nilai tabel pada derajat bebas 56 dan taraf nyata 0,05 sebesar 2,003 . Apabila dilakukan pembandingan maka $\left|\mathrm{t}_{\text {hitung }}\right|<\mathrm{t}_{\text {tabel }}$ atau nilai signifikansi $>$ 0,05 dan disimpulkan Ho diterima yang berarti bahwa tidak terdapat perbedaan yang signifikan hasil posttest antara kelas eksperimen model pembelajaran Kancing Gemerincing dan Jigsaw.

Hasil penelitian didapatkan nilai rata-rata pre-test yang didapatkan kelas V-A yang diajarkan menggunakan model pembelajaran Kancing Gemerincing adalah 70,17 dan nilai rata-rata post-test adalah 81,21 . Sedangkan nilai rata-rata pre-test yang didapatkan kelas V-B yang diajarkan menggunakan model pembelajaran Jigsaw adalah 70,00 dan nilai rata-rata post-test adalah 75,17 .

Peningkatan hasil belajar siswa kelas V-A yang diajarkan dengan menggunakan model pembelajaran Kancing Gemerincing yaitu 11,04 dan nilai rata-rata peningkatan hasil belajar siswa kelas V-B yang diajarkan dengan menggunakan model pembelajaran Jigsaw sebesar 5,17. Hal ini menunjukan bahwa terjadi peningkatan nilai rata-rata siswa yang dibelajarkan menggunakan model pembelajaran Kancing Gemerincing dan Jigsaw, namun nilai rata-rata siswa yang dibelajarkan melalui model pembelajaran Kancing Gemerincing lebih baik dibandingkan dengan kemampuan kognitif siswa yang diajarkan dengan menggunakan model pembelajaran Jigsaw.

Perbedaaan kemampuan kognitif siswa antara siswa yang dibelajarkan dengan menggunakan model pembelajaran Kancing Gemerincing dan Jigsaw diketahui dengan menggunakan uji hipotesis menggunakan uji-t dua sampel tidak berhubungan (Indepensent Sampel T-Test) dengan bantuan progam SPSS 17 for windows.

Hasil analisis data menggunakan Independent sample t-test adalah nilai signifikansi pre-test sebesar 0,979 atau nilai signifikansi > 0,05 dan disimpulkan
Ho diterima yang bearti tidak terdapat perbedaan yang signifikan nilai pre-test antara kelas eksperimen Kancing Gemerincing dan Jigsaw. Pada hasil nilai post-test nilai signifikansi sebesar 0,336 atau nilai signifikansi $>0,05$ dan disimpulkan Ho diterima yang bearti tidak terdapat perbedaan yang signifikan nilai post-test antara kelas eksperimen Kancing Gemerincing dan Jigsaw.

Tidak adanya perbedaan ini dapat disebabkan oleh beberapa faktor, kedua model pembelajaran ini sama-sama berbasis kontruktivisme. Siswa pada kedua kelas sama-sama membangun pengetahuannya sendiri dan melakukan investigasi untuk membuktikan pengetahuannya.

\section{SIMPULAN}

Berdasarkan analisis statistik diperoleh diperoleh nilai $t_{\text {hitung }}$ sebesar $-0,970$ dengan nilai signifikansi sebesar 0,336 . Nilai tabel pada derajat bebas 56 dan taraf nyata 0,05 sebesar 2,003. Apabila dilakukan pembandingan maka $\left|t_{\text {hitung }}\right|<t_{\text {tabel }}$ atau nilai signifikansi $>0,05$ dan disimpulkan Ho diterima yang berarti bahwa tidak terdapat perbedaan yang signifikan kemampuan kognitif siswa yang menggunakan model pembelajaran Kancing Gemerincing dan Jigsaw dalam pembelajaran tematik, tema 9 sub tema 3, pembelajaran 4.

Berdasarkan hasil penelitian dapat disarankan :

1. Perlu adanya penelitian lebih lanjut untuk mengetahui apakah model pembelajaran Kancing Gemerincing dan Jigsaw dapat diterapkan serta memberikan hasil dan perbedaan yang lebih baik lagi pada topik maupun pembelajaran yang lain.

2. Bagi peneliti selanjutnya hendaknya memperhatikan intrumen soal dengan baik mulai validitas, reliabilitas, tingkat kesukaran, daya beda agar hasil penelitian bisa maksimal.

3. Guru diharapkan mempunyai pengetahuan dan kemampuan yang cukup untuk memilih model pembelajaran yang tepat dan sesuai dengan materi yang akan diiajarkan. 


\section{DAFTAR PUSTAKA}

Arikunto, S. 2008. Dasar-dasar Evaluasi Pendidikan. Jakarta: Bumi Aksara.

Arikunto, S. 2002. Prosedur Penelitian. Jakarta: Rineka Cipta.

Amri, S. 2013. Pengembangan dan Model Pembelajaran dalam Kurikulum 2013. Jakarta: PT. Prestasi Pustakarya.

Anwar. 2008. Life Skill Education. Bandung: Alfabeta.

Azizah, D. N. 2013. Penerapan Metode Jigsaw untuk Meningkatkan Hasil Belajar IPA pada Materi Cuaca Siswa kelas III SDN Plosogeneng Jombang. Malang: FKIP Universitas Muhammadiyah Malang.

Chotimah, H. 2010. Pengaruh Model Pembelajaran Jigsaw Terhadap Hasil Belajar Mata Pelajaran Matematika pada Siswa kelas V SD Sidomulyo Tulungagung. Malang : FKIP Universitas Negeri Malang.

Djaali, H. 2006. Psikologi Pendidikan. Jakarta: Bumi Aksara.

Djamarah, S. B. dan Aswan Z. 2010. Strategi Belajar Mengajar. Jakarta: PT. Rineka Cipta.

Gunawan, M. A. 2013. Statistik untuk Penelitian Pendidikan. Yogyakarta: Pazama Publishing.

Hajar, I. 2013. Paduan Lengkap Kurikulum Tematik. Jogjakarta: Diva Press.

Hajar, I. 2009. Dasar-dasar Metodologi Penelitian Kwantitatif dalam Pendidikan. Jakarta: PT. Raja Grafindo Persada.

Harsyiwi, R. T. Penerapan Model Pembelajaran Kooperatif Teknik Kancing Gemerincing untuk Meningkatkan Hasil Belajar Matematika Materi Operasi
Perkalian dan Pembagian Siswa Kelas VI SD Negeri 1 Kembang Kabupaten Jepara. Malang: FKIP Universitas Muhammadiyah Malang.

Hasbullah. 2006. Dasar-dasar Ilmu Pendidikan. Jakarta: Grafindo.

Hidayat, S. 2013. Pengembangan Kurikulum Baru. Bandung: PT. Remaja Rosdakarya.

Huda, M. 2012. Cooperative Learning. Yogyakarta: Pustaka Belajar.

Ilma, A. N. 2010. Perbedaan Kemampuan Kognitif dan Ketrampilan Kooperatif Model Jigsaw dan Cooperatif Script Siswa Kelas VII MTS Muhammadiyah 1 Malang. Malang: FKIP Universitas Muhammadiyah Malang.

Isjoni. 2011. Cooperative Learning. Bandung: Alfabeta.

Kunandar. 2007. Guru Profesional: Implementasi Kurikulum Tingkat Satuan Pendidikan (KTSP) dan Persiapan Menghadapi Sertifikasi Guru. Jakarta: PT. Raja Grafindo Persada.

Kusuwana, W. S. 2012. Taksonomi Kognitif. Bandung: PT. Remaja Rosdakarya.

Majid, A. 2013. Strategi Pembelajaran. Bandung: PT. Remaja Rosdakarya.

Mulyasa, E. 2014. Pengembangan dan Implementasi Kurikulum 2013. Bandung: PT. Remaja Rosdakarya.

Nurhadi \& Senduk A. G. 2009. Pembelajaran Kontekstual. Surabaya: Jepe Press Media Utama.

Purwanto. 2011. Statistika untuk Penelitian. Surakarta: Pustaka Belajar. 
Purwanto. 2008. Penelitian Kuantitatif untuk Psikologi Pendidikan. Yogyakarta: Pustaka Pelajar.

Purwanto. 2014. Evaluasi Hasil Belajar. Yogyakarta: Pustaka Pelajar.

Rasyid, H. dan Mansyur. 2007. Penilaian Hasil Belajar . Bandung:CV Wacana Prima.

Rusman. 2010. Model-model Pembelajaran. Depok: PT. Raja Grafindo Persada.

Sanjaya,W. 2006. Strategi Pembelajaran Berorientasi Standar Proses Pendidikan. Jakarta: Kencana Media.

Siregar, S. 2011. Statistika Deskriptif untuk Penelitian. Jakarta: PT. Raja Grafindo Persada.

Sari, L. W. P. 2013. Pengaruh Model Pembelajaran Kooperatif Tipe TGT dengan Berbantuan Media Puzzle terhadap Hasil Belajar IPA Siswa Kelas 4 SD Negeri Candi Garon 1 Tahun Pelajaran 2012-2013.

Universitas Kristen Satya.

Slavin, E. R. 2005. Cooperative Learning. Bandung: Nusa Media.

Sudjana, N. 2013. Penilaian Hasil Proses Belajar Mengajar. Bandung: PT. Remaja Rosdakarya.

Sugiyono. 2005. Statistik untuk Penelitian. Bandung: Alfabeta.

Sugiyono, 2012. Statistika untuk Penelitian. Bandung : Alfabeta.

Sukmadinata, N. 2013. Metode Penelitian Pendidikan. Bandung: PT. Remaja Rosdakarya.

Suprijono, A. 2009. Cooperative Learning. Yogyakarta: Pustaka Belajar.

Sutirjo dan Sri I. M. 2005. Tematik: Pembelajaran Efektif dalam kurikulum 2004. Malang: Bayumedia Publishing.
Shoimin,A.2014. $68 \quad$ Model Pembelajaran Inovatif dalam Kurikulum 2013.Yogyakarta: Arruzz Media.

Syah, M. 2003. Psikologi Belajar. Jakarta: Grafindo.

Tim Dosen UMM. 2010. Bahasa Indonesia untuk Karangan Ilimiah. Malang : UMM Press.

Yamin, M. 2013. Strategi \& Metode dalam Model Pembelajaran. Jakarta: Referensi (GP Press Group).

Warsono dan Hariyanto. 2012. Pembelajaran Aktif. Bandung: PT. Remaja Rosdakarya.

Winarsunu, T. 2009. Statistika dalam Penelitian Psikologi dan Pendidikan. Malang: Umm Press. 